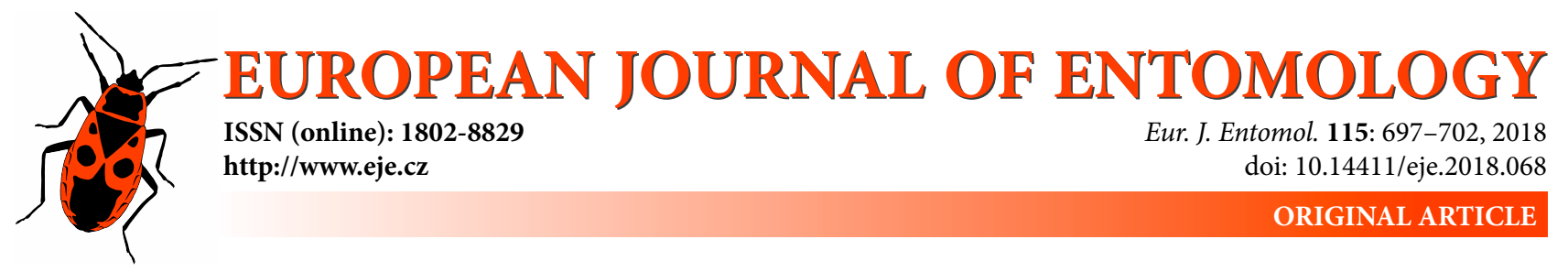

\title{
Regulation of larval diapause by colony-founding queens of Crematogaster teranishii (Hymenoptera: Formicidae)
}

\section{KEIJI NAKAMURA}

Department of Biosphere-Geosphere Science, Faculty of Biosphere-Geosphere Science, Okayama University of Science, Ridai-cho 1-1, Okayama 700-0005, Japan; e-mail: nakamura@big.ous.ac.jp

\begin{abstract}
Keywords. Hymenoptera, Formicidae, colony development, ant, larval diapause, reproductive diapause of queens, low temperature, social effect
\end{abstract}

\begin{abstract}
Nuptial flights of Crematogaster teranishii Santschi occur in autumn. Queens and possibly larvae pass the first winter without workers in Okayama, Japan. This study examines and tests the hypothesis that $C$. teranishii queens regulate not only their own diapause, but also that of their larvae. Some queens collected immediately after their nuptial flight in early October were exposed to a low temperature of $10^{\circ} \mathrm{C}$ for 3 months before transfer to $25^{\circ} \mathrm{C}$; these queens started oviposition approximately 8 days after the transfer. Larvae reared by these previously chilled queens pupated synchronously until day 50 . Other field-collected queens reared at $25^{\circ} \mathrm{C}$ without prior chilling reproduced soon after collection. They started oviposition, but the development of their larvae was arrested and pupation occurred late or not at all within the 120 day experimental period. The delay in pupation in colonies in which the queens were not previously exposed to low temperature strongly indicates that many larvae are in diapause. Because eggs and larvae were not exposed to low temperatures, they were unable to determine the developmental pathway providing the best response to environmental factors. Results indicate that queens regulate whether their larvae undergo diapause.
\end{abstract}

\section{INTRODUCTION}

Diapause, which plays an important role in the seasonal regulation of insect life cycles (Danks, 1987), is an important adaptation to low temperatures in temperate climates and is induced in species-specific developmental stages. Intermediary and respiratory metabolism is suppressed in diapausing insects (Hahn \& Denlinger, 2011). Diapause is a dynamic state of low metabolism that is unlike quiescence, an immediate response to adverse environmental conditions that can occur at any stage in a life cycle. Many insects living in temperate areas enter facultative diapause in response to specific environmental cues, such as short day length and low temperature (Tauber et al., 1986; Danks, 1987; Koštál, 2006). In insects with an obligate diapause, development or reproduction is arrested at the same developmental stage in every generation, irrespective of environmental conditions.

For ants in tropical or subtropical regions, colony development and oviposition by the queen occur throughout the year (Kipyatkov, 2001a). For ant species at higher latitudes, however, winter diapause regulates when queens oviposit and larval development (Kipyatkov, 2001a). In warm climates, low temperature is the primary environmental stimulus inducing facultative diapause (Kipyatkov, 1993, 2001a). For example, queens of Lasius niger continue ovipositing for more than 100 days at $25^{\circ} \mathrm{C}$, but they stop ovi- positing within approximately 20 days at $20^{\circ} \mathrm{C}$ (Kipyatkov, 1993). The cessation of oviposition by queens when it is warm is not the result of quiescence but because they are in reproductive diapause. In addition, in a Japanese population of Lasius japonicus, reproductive diapause in queens and larvae is induced, respectively, at constant $15^{\circ} \mathrm{C}$ and $17.5^{\circ} \mathrm{C}$ (Kamitani et al., 2015; Nakamura et al., 2017). In most species of ants, day length plays no role in the induction of diapause, probably because nests are constructed underground. Ants at high latitudes often enter diapause endogenously after a certain period of reproduction and development. Repeated induction of reproductive diapause in queen ants occurs irrespective of environmental stimuli, similar to the obligatory diapause in other insects (Kipyatkov, 1993, 2001a).

Social regulation of diapause also occurs in several ants (Kipyatkov, 1993, 2001a). Specifically, workers might influence the diapause of queens or larvae. For instance, larvae tend to emerge as workers without entering diapause if they are reared by workers that have overwintered or which experience low temperatures in the laboratory (e.g., Brian, 1955; Weir, 1959; Kipyatkov et al., 1996, 1997; Kipyatkov \& Lopatina, 1999). In contrast, larvae tend to enter diapause if they are reared by workers that are not exposed to low temperatures. 
In temperate regions, in response to day length, many insects are in diapause during winter (Lees, 1955; Danilevsky, 1961; Tauber et al., 1986; Danks, 1987; Koštál, 2006). Specifically, short day lengths might play a crucially important role in the induction of diapause. Although low temperature is the primary environmental stimulus for diapause induction in ants, photoperiod might also affect the regulation of diapause in some species of ants (Kipyatkov, 1993, 2001a). In Lepisiota semenovi, diapause in queens and larvae is induced earlier under a short-day photoperiod than under a long-day photoperiod (Kipyatkov \& Lopatina, 2009). In Myrmica rubra, larval development and diapause regulation are regulated by workers that perceived the daylength outside the nest (Kipyatkov, 2001b).

Seasonal regulation of the life cycles of Japanese ants is not well studied. In Amblyopone silvestrii Wheeler, a seasonal pattern of colony development is recorded: the eggs, first instar larvae, pupae and callow adults are found mainly in summer (Masuko, 2003b). Reproductive workers of the Japanese queenless ant, Pristomyrmex pungens, lay eggs under a long-day photoperiod. They enter diapause under a short-day photoperiod (Muramatsu \& Numata, 2002). Colony development in Lasius japonicus in Okayama is unaffected by photoperiod, but is highly dependent on the rearing temperature (Kamitani et al., 2015; Nakamura et al., 2017). Specifically, colony development is rapid at $25^{\circ} \mathrm{C}$, although larval diapause and reproductive diapause in queens are induced respectively at $20^{\circ} \mathrm{C}$ and $15^{\circ} \mathrm{C}$. Despite the paucity of such examples, the studies cited above illustrate the diversity of seasonal colony development among Japanese species of ants.

Many species of ants exhibit claustral colony founding. Newly mated queens use nutrient reserves to found a colony with no help from workers (Hölldobler \& Wilson, 1990). After the workers emerge, the colony development is highly dependent on the social conditions in the nest, such as the size and structure of the population and the age of workers (e.g., Brian, 1953, 1957a, b; Schneirla, 1957; Tschinkel, 1988; Børgesen \& Jensen, 1995; Masuko, 2003a).

In a warm climate, ants can produce several broods before winter, and facultative diapause is induced in queens and larvae (Kipyatkov, 2001a). Consequently, diapause can be induced even in insects in nests constructed underground. Workers in an autumnal physiological condition can induce larval diapause, whereas those in a spring physiological condition avert diapause. The present study was conducted based on the assumption that solitary queens of Crematogaster teranishii Santschi soon after overwintering are able to regulate larval diapause. In this study, this assumption is tested by comparing colony development by founding queens under different experimental conditions. Crematogaster teranishii Santschi is a tree-nesting ant distributed in Japan and Korea (JADG, 2003). Nuptial flights of C. teranishii occur in September and October in Okayama City (Kuroki, unpubl. observ.). Some queens collected immediately after their nuptial flight were reared at a moderate temperature; others were exposed to low tempera- tures before rearing under moderate conditions. Effects of photoperiod on colony development were also recorded. Results indicate that queens of $C$. teranishii regulate the seasonal development of their colonies.

\section{MATERIALS AND METHODS}

\section{Collection and rearing of insects}

Within a few hours of their nuptial flight, approximately 150 queens of C. teranishii were collected in Okayama City $\left(34.7^{\circ} \mathrm{N}\right.$, $133.9^{\circ} \mathrm{E}$ ), Japan during 9-16 October, 2007. After transfer to one of the experimental conditions within a few hours of their collection, they were reared separately in plastic containers $(70 \times 40$ $\mathrm{mm}, 20 \mathrm{~mm}$ deep). Queens that failed to shed their wings were not used in the experiments. The bottom of the rearing containers was covered with plaster. Water was provided ad libitum. $C$. teranishii exhibits claustral colony founding. Therefore, food was not provided until the first worker emerged as an adult. After the workers emerged, dried bloodworm and an artificial diet for adult beetles (Fujikon Co. Ltd., Nose, Osaka, Japan) were supplied twice a week as food.

Brood development in colonies of which the queens were exposed to low temperatures before transfer to $25^{\circ} \mathrm{C}$

Within a few hours of collection, 43 queens were transferred to $12 \mathrm{~L}: 12 \mathrm{D}$ at $10^{\circ} \mathrm{C}$ and reared individually. After exposure for 90 days to $10^{\circ} \mathrm{C}$, they were divided into two groups and reared at $25^{\circ} \mathrm{C}$ under either the long-day or short-day photoperiod $(n=$ 22 and 21, respectively, under 16L:8D and 12L:12D). Mortality of the queens was recorded daily from the transfer to $25^{\circ} \mathrm{C}$ (day $0)$ to the end of the experiment, 90 days later. The eggs, larvae, pupae and worker adults were counted daily from day 0 to day 60 . Thereafter, because of the increase in the number of fast-moving workers, the insects were not counted; the existence of eggs, larvae, pupae and adult workers was recorded daily until day 90 .

\section{Brood development by queens that were not exposed to low temperature}

A total of 42 queens were reared at $25^{\circ} \mathrm{C}$ in the laboratory within a few hours of collection. Under a long-day photoperiod of $16 \mathrm{~L}$ : $8 \mathrm{D}$ or a short-day photoperiod of $12 \mathrm{~L}: 12 \mathrm{D}$ at $25^{\circ} \mathrm{C}, 21$ queens were reared individually. The mortality of queens was recorded daily from the collection of queens (day 0 ) to the end of the experiment on day 120 . The eggs, larvae, pupae and worker adults were counted daily from day 0 to day 120 .

\section{Brood development under field conditions}

To clarify the timing of colony development outdoors, 24 queens collected during 9-16 October, 2007 were reared individually under natural conditions. Plastic containers were placed on the campus of the Okayama University of Science in areas not exposed to direct sunlight. The rearing procedure was the same as that used for laboratory insects. Mortality of queens and existence of eggs, larvae, pupae and adult workers were recorded once a week until 30 September, 2008.

\section{Data analysis}

For this study, the pre-oviposition period and date of first appearance of larvae, pupae and workers were recorded from the time the queens were transferred to $25^{\circ} \mathrm{C}$. The period spent at $10^{\circ} \mathrm{C}$ was excluded from calculations. Average values of the preoviposition period and date of first appearance of larvae were analyzed using two-way analysis of variance (ANOVA). This statistical analysis was done using "ANOVA 4 on the Web", available on the internet (http://www.hju.ac.jp/ Kkiriki/anova4/about.html). Percentages of colonies with pupae and workers on day 90 in the 


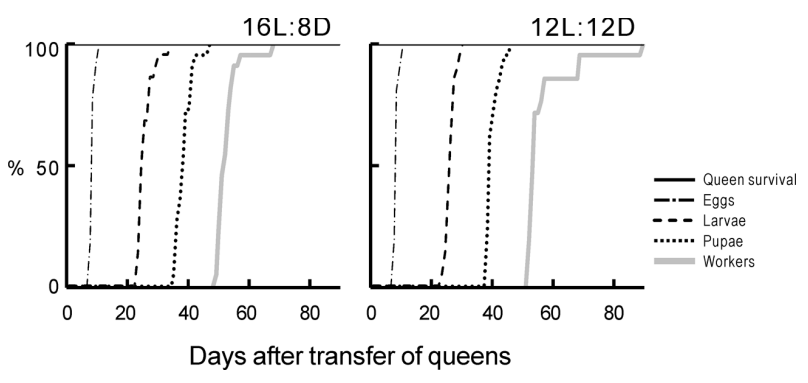

Fig. 1. The percentage survival of queens of Crematogaster teranishii and cumulative percentage of colonies in which eggs, larvae, pupae and workers were recorded in the laboratory at $25^{\circ} \mathrm{C}$ : queens were exposed to $10^{\circ} \mathrm{C}$ for 90 days before being transferred to $25^{\circ} \mathrm{C} ; N=22$ and 21 , respectively, under $16 \mathrm{~L}: 8 \mathrm{D}$ and $12 \mathrm{~L}: 12 \mathrm{D}$.

laboratory were arcsine-transformed and assessed using ANOVA/ Tukey's test with a significance level of $p=0.05$ (Zar, 2010).

\section{RESULTS}

\section{Brood development in colonies of which the queens were exposed to low temperatures before transfer to $25^{\circ} \mathrm{C}$}

After 90 days of exposure to $10^{\circ} \mathrm{C}$, all the queens started ovipositing synchronously less than 10 days after the transfer to $25^{\circ} \mathrm{C}$ (Fig. 1). The average length of the period between the transfer to $25^{\circ} \mathrm{C}$ and start of oviposition was 8.1 \pm 0.8 days, irrespective of the photoperiod ( $n=22$ and 21 , respectively, under $16 \mathrm{~L}: 8 \mathrm{D}$ and $12 \mathrm{~L}: 12 \mathrm{D})$. First appearances of larvae were $25.5 \pm 1.7$ and $26.0 \pm 1.5$ days, respectively, under 16L:8D and 12L:12D. Pupation occurred synchronously approximately 15 days after the emergence of larvae. Average ( \pm S.D.) length of the periods to first appearance of pupae were, respectively, $38.6 \pm 1.8$ and 40.0 \pm 1.7 days under $16 \mathrm{~L}: 8 \mathrm{D}$ and $12 \mathrm{~L}: 12 \mathrm{D}$. Workers emerged in all colonies during the experimental period. The average ( \pm S.D.) lengths of the periods to first appearance of worker adults were, respectively, $52.9 \pm 1.8$ and $56.9 \pm 4.9$ days under $16 \mathrm{~L}: 8 \mathrm{D}$ and $12 \mathrm{~L}: 12 \mathrm{D}$. On average the date of first appearance of both pupae and workers, did not differ significantly under the two photoperiods $(p>0.05$, unpaired $t$-test, $t(41)=1.775$ and 1.947 for pupae and workers, respectively).

\section{Development of brood by queens that were not exposed to low temperature}

When queens that had just been collected were reared at a constant $25^{\circ} \mathrm{C}$ without chilling, only one queen under each photoperiod died without ovipositing (Fig. 2). Oviposition was recorded on the day following the collection of the queens (day 1); by day 22 and 17, all queens had started ovipositing under 16L:8D and 12L:12D, respectively. Average $( \pm$ S.D.) lengths of the periods between the collection of queens and first oviposition were $9.0 \pm 5.2$ days $(n=20)$ and $7.7 \pm 3.8$ days $(n=20)$, respectively, under $16 \mathrm{~L}: 8 \mathrm{D}$ and $12 \mathrm{~L}: 12 \mathrm{D}$. Hatching occurred approximately 25 days after the collection of queens. Average number of days from queen collection to first appearance of larvae were $27.5 \pm 5.5(n=20)$ and $25.6 \pm 5.0$ days $(n=19)$, respectively, under $16 \mathrm{~L}: 8 \mathrm{D}$ and $12 \mathrm{~L}: 12 \mathrm{D}$.

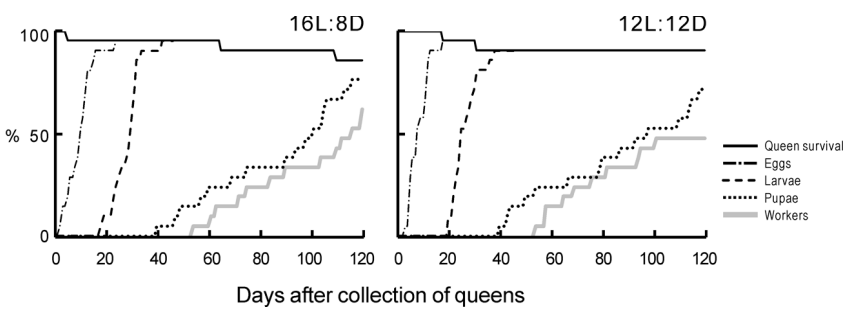

Fig. 2. The percentage survival of queens of Crematogaster teranishii and cumulative percentage of colonies in which eggs, larvae, pupae and workers were recorded in the laboratory at $25^{\circ} \mathrm{C}$ : queens were not previously exposed to low temperatures; $N=21$ in each photoperiod.

In 17 and 15 of the colonies under 16L:8D and $12 \mathrm{~L}: 12 \mathrm{D}$, respectively, pupae had developed by the end of the experiment on day 120 . However, the onset of pupation was not synchronized among colonies. Pupation was first observed at approximately day 40. Thereafter, pupation began in only 1-3 colonies during each 10-day interval. As a result, the emergence of adult workers was not synchronized among colonies. On day 120, there was no adult emergence in 7 and 9 colonies, respectively, under $16 \mathrm{~L}: 8 \mathrm{D}$ and $12 \mathrm{~L}: 12 \mathrm{D}$.

\section{Comparison of brood development in the experimental treatments}

Two-way ANOVA (Table 1) was conducted to test the effects of exposure to low temperature and different photoperiods on the length of the periods between the start of rearing at $25^{\circ} \mathrm{C}$ and first oviposition and hatching date. Chilling, photoperiod, or interaction between chilling and photoperiod, did not have a significant effect. Percentages of colonies with pupae on day 90 in the four experimental treatments were compared. The percentages of those that were chilled ( $100 \%$ under each photoperiod) were significantly higher than those that were not $(44.4$ and $47.3 \%$, respectively, under $16 \mathrm{~L}: 8 \mathrm{D}$ and $12 \mathrm{~L}: 12 \mathrm{D})(p<0.05$, Tukey's test, $q=6.79$ and 6.51 , respectively, under $16 \mathrm{~L}: 8 \mathrm{D}$ and 12L:12D). There were no significant differences in the results recorded under the two photoperiods $(p>0.05$, Tukey's test, $q=0.022$ and 0.248 , respectively, in experiments with and without chilling). Similarly, the percentages of colonies with workers on day 90 were significantly higher for those with queens that were previously chilled than not chilled ( $p<0.05$, Tukey's test, $q=7.65$ and 7.90, respectively, under $16 \mathrm{~L}: 8 \mathrm{D}$ and $12 \mathrm{~L}: 12 \mathrm{D})$; no significant differences were found between photoperiods $(p>0.05$, Tukey's test, $q=0.022$ and 0.156 , respectively, in experiments with and without chilling).

Table 1. Summary of the results of the two-way ANOVA testing for the effects of chilling and photoperiod on the pre-oviposition period and date of first appearance of larvae.

\begin{tabular}{|c|c|c|c|c|c|c|}
\hline \multirow[t]{2}{*}{ Sources of variation } & \multicolumn{3}{|c|}{$\begin{array}{l}\text { Pre-oviposition } \\
\text { period }\end{array}$} & \multicolumn{3}{|c|}{$\begin{array}{c}\text { Date of first } \\
\text { appearance of larvae }\end{array}$} \\
\hline & df $M S$ & $F$ & $P$ & df $M S$ & $F$ & $P$ \\
\hline & 110.49 & 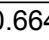 & 418 & 11.136 & .11 & .741 \\
\hline ho & 111.0 & & 405 & 19.3 & & .34 \\
\hline Chilling $\times$ Photoperiod & 131.32 & 98 & .163 & 18.20 & 70 & .376 \\
\hline
\end{tabular}




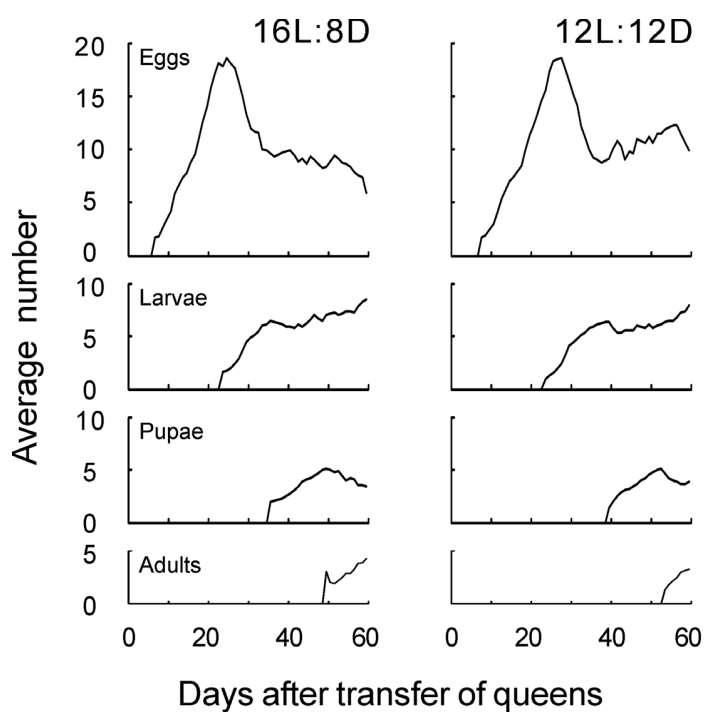

Fig. 3. Effects of photoperiod on the mean number of eggs, larvae, pupae and worker adults of Crematogaster teranishii recorded at $25^{\circ} \mathrm{C}$. Queens were exposed to $10^{\circ} \mathrm{C}$ for 90 days before transfer to $25^{\circ} \mathrm{C}: N=22$ and 21 , respectively, at $16 \mathrm{~L}: 8 \mathrm{D}$ and $12 \mathrm{~L}: 12 \mathrm{D}$.

The number of eggs in colonies with queens that were previously chilled increased steeply until approximately day 25 (Fig. 3). The average numbers of eggs on day 25 were $18.4 \pm 5.4$ and $19.0 \pm 4.1$, respectively, under L16:8D and 12L:12D. There was no significant difference between the photoperiods ( $p>0.05$, unpaired $t$-test, $t(42)=0.285)$. Subsequently, the number of eggs decreased and larvae hatched. About seven larvae, on average, were recorded between days 30 and 40 . The numbers of pupae were slightly less than those of larvae because some larvae died during the experiments. Workers started emerging on approximately day 50 .

In colonies with queens that were not chilled, the mean number of eggs increased continuously for more than 20 days, after which the number decreased (Fig. 4). The average numbers of eggs on days 20-30 were approximately 10, both under L16:D8 and L12 : D12. Eggs were present continuously throughout the experimental period. Larvae began hatching from eggs on approximately day 20 . The number of larvae increased to about five per colony; then the number remained constant during the experimental pe-

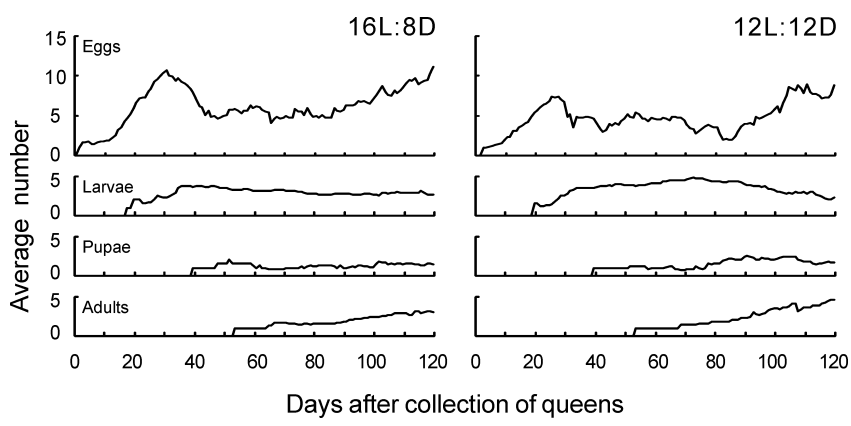

Fig. 4. Effects of photoperiod on the mean number of eggs, larvae, pupae and worker adults of Crematogaster teranishii recorded at $25^{\circ} \mathrm{C}$. Queens were not exposed to low temperatures; $N=21$ at each photoperiod.

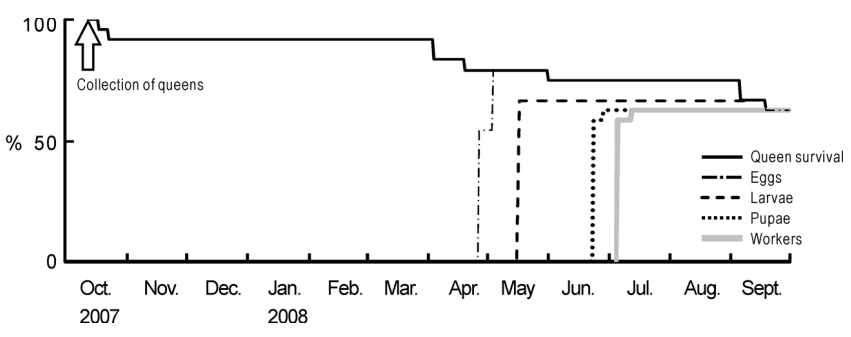

Fig. 5. The percentage survival of queens of Crematogaster teranishii and cumulative percentage of colonies in which eggs, larvae, pupae and workers were recorded under outdoor conditions; $N=$ 24.

riod. The maximum numbers of larvae were less than half of the number of eggs, probably because many eggs were consumed by the larvae. In addition, lower numbers of pupae were recorded than of larvae, indicating that many larvae were in diapause. Workers began emerging on approximately day 50 and their numbers increased gradually during the course of the experiment.

\section{Brood development under field conditions}

Only 1 of 24 queens started ovipositing before winter. However, the eggs laid in October disappeared from the colony in November without hatching and the queen did not lay any more eggs until the following spring. Consequently, this result is not presented in the figure. In autumn and early spring, five queens died without ovipositing (Fig. 5). In the remaining 19 colonies, queens started oviposition between 27 April and 4 May; hatching was recorded on the same day in all colonies, 25 May. During May-September, four queens died, and in all these cases hatching and pupation did not occur. In the remaining 15 colonies, pupae and workers, respectively, started emerging 23-30 June and 6-13 July. In all the colonies where workers emerged, queens survived until the end of the experiment, on 30 September.

\section{DISCUSSION}

\section{Effects of temperature and queens on larval development and diapause induction}

Comparison of the average number of days between the transfer of queens to $25^{\circ} \mathrm{C}$ and first oviposition or hatching in the different experimental treatments revealed no significant effect of chilling (Table 1). However, exposure of queens to $10^{\circ} \mathrm{C}$ affected the date of first appearance of pupae and workers (Figs 1-2). Pupae developed synchronously until day 50 in these colonies. However, in colonies the queens of which were not previously chilled, pupation either occurred late or did not occur within the 120 day experimental period. The delay in pupation in colonies with queens that were not previously chilled strongly indicates that many larvae were in diapause. Also in M. rubra, diapause is induced in larvae produced in summer (Brian, 1962). In addition, queens of M. rubra emerge from larvae that overwintered.

The numbers of eggs were greater than those of larvae (Figs 3-4), indicating that unhatched eggs were consumed by larvae. In colonies with queens that were not previous- 
ly chilled, approximately 5 or more unhatched eggs were recorded throughout the experimental period. However, pupation was delayed or did not occur. Consequently, it is likely that feeding in larvae is suppressed, despite the existence of food at the warm temperature of $25^{\circ} \mathrm{C}$. Because diapause is usually accompanied by a decrease in food consumption and metabolic rate (Lees, 1955; Tauber et al., 1986; Danks, 1987), these findings might confirm that the larvae are in diapause.

Eggs and larvae were not exposed to low temperatures. Therefore, the developmental pathway in response to environmental factors was not determined. The only differences between experimental treatments were the age and physiological status of the queens. Consequently, one might infer that the queens can regulate the induction of facultative diapause in larvae.

For some ants, workers after overwintering or after experimental exposure to low temperatures, are able to terminate larval diapause and induce metamorphosis (Brian, 1955, 1962; Weir, 1959; Kipyatkov et al., 1997; Kipyatkov \& Lopatina, 1999). Brian (1955) records the development and metamorphosis of diapausing larvae that were cared for by workers in two contrasting physiological states: spring and autumnal workers. Consequently, spring workers kept in a refrigerator over a prolonged period stimulated pupation, whereas the larvae that were fed by autumnal workers did not develop further. Although the experimental treatments used in this study differ slightly from those of earlier studies, the present results confirm that adults exposed to low temperatures produce larvae that do not undergo diapause.

Mediation of larval diapause by workers is recorded for some species of ants (Hölldobler \& Wilson, 1990). In a warm temperate climate, ants can produce more than one brood per season. For instance, in Okayama, the nuptial flights of queens of L. japonicus occur in early summer and they then produce several broods before winter (Kamitani et al., 2015). Consequently, in autumn, larvae in these nests must enter diapause. The regulation of facultative larval diapause by adults might enable ants in warm climates to cease colony development in the most appropriate season. It might also enable them to produce as many broods as possible before winter.

Earlier studies used colonies with both queens and workers. Therefore, the physiological status of the workers is emphasized. For instance, Brian (1973a) reports that queens of $M$. rubra do not act directly on the larvae but change the way workers treat the larvae. In contrast, results of the present study indicate that a queen of $C$. teranishii can regulate larval diapause even in the absence of workers.

There were no adult workers present in the colonies used in the current study. Therefore, it is unlikely that substances or food brought from outside of the nest are necessary for the regulation of larval diapause in $C$. teranishii. Nevertheless, it remains unclear how queens induce larval diapause. Studies have shown that several candidate factors, such as chemical substances or pheromones, regulate larval growth and development in ants (Brian, 1970, 1973a; Kipyatkov, 2001b) as well as physical contact (Brian, 1973b). Even the possibility that queens alter the quality or quantity of the larval diet through trophic eggs or glandular secretion cannot be denied. Moreover, queens may lay eggs that produce larvae that are destined to enter diapause because maternal induction of larval diapause occurs in insects, including Hymenoptera (Mousseau \& Dingle, 1991). Therefore, additional experiments are needed to elucidate the mechanism inducing diapause in larvae of C. teranishii.

\section{Reproductive diapause of queens}

When queens of $C$. teranishii were transferred from the field directly to $25^{\circ} \mathrm{C}$, oviposition was recorded one day after the queens were collected. This indicates that some of the queens were not in diapause, but were reproductive at the time of the nuptial flight. After exposure to low temperature, however, all the queens started ovipositing approximately 1 week after transfer to $25^{\circ} \mathrm{C}$. Although no significant difference was found in the pre-oviposition period between those that were and were not previously chilled, the 1-week delay in oviposition indicates that after chilling queens do not have mature eggs in their ovaries. Ants in tropical or subtropical regions do not diapause; quiescence is induced directly by low temperature. Also in many ants in warm temperate climates, low temperature in autumn arrests oviposition by queens. However, queens stop oviposition even at relatively warm temperatures, indicating that facultative diapause is induced (Kipyatkov, 1993, 2001a). For example, queens of Lasius japonicus from Okayama enter diapause when reared under constant $15^{\circ} \mathrm{C}$ (Kamitani et al., 2015). Results of the present study may indicate that reproductive diapause in queens of C. teranishii is also induced by low temperature. In the present study, however, the effect of low temperatures was unclear. To verify whether or not queens enter reproductive diapause, more sophisticated experiments, including moderately low temperatures, are necessary.

It is also noteworthy that the pre-oviposition period at $25^{\circ} \mathrm{C}$ was short and synchronized in queens after 90 days of chilling ( $8.1 \pm 0.8$ under both $16 \mathrm{~L}: 8 \mathrm{D}$ and $12 \mathrm{~L}: 12 \mathrm{D})$. Low temperatures often play a role in the termination of winter diapause (Andrewartha, 1952; Lees, 1955; Danilevsky, 1961; Tauber et al., 1986; Danks, 1987; Košt’ál, 2006). The results obtained in the present study indicate that reproductive diapause in queens is not only induced but also terminated by exposure to low-temperature. One adaptive advantage of diapause is the synchronization of reproduction within a population (Tauber et al., 1986). Although synchronization of reproduction among colonies is not necessary for inseminated ant queens, it might be adaptive for every queen after overwintering to initiate oviposition and colony development as early as possible.

\section{Photoperiod effects}

Day length is the most important environmental factor regulating seasonal development in insects in temperate regions (Tauber et al., 1986; Danks, 1987; Košt’ál, 2006). Although photoperiod might also affect the regulation of 
diapause in some species of ants (Brian, 1986; Kipyatkov, 1993, 2001a), day length plays no role in the induction of diapause in many ants (Kipyatkov, 1993, 2001a). In the present study, there was no clear difference between the effect of long-day and short-day photoperiods (Figs 1-4, Table 1). The present findings confirm that even in $C$. teranishii photoperiod does not play a role in the induction of diapause in either queens or larvae.

ACKNOWLEDGEMENTS. We thank I. Kuroki for his cooperation.

\section{REFERENCES}

Andrewartha H.G. 1952: Diapause in relation to the ecology of insects. - Biol. Rev. 27: 50-107.

BørGESEN L.W. \& JENSEN P.V. 1995: Influence of larvae and workers on egg production of queens of the pharaoh's ant, Monomorium pharaonis (L.). - Insectes Soc. 42: 103-112.

BRIAN M.V. 1953: Brood rearing in relation to worker number in the ant Myrmica. - Physiol. Zool. 26: 355-366.

Brian M.V. 1955: Studies of caste differentiation in Myrmica rubra L. 3. Larval dormancy, winter size and vernalisation. Insectes Soc. 2: 85-114.

BRIAN M.V. 1957a: The growth and development of colonies of the ant Myrmica. - Insectes Soc. 4: 177-190.

BRIAN M.V. 1957b: Serial organization of brood in Myrmica. Insectes Soc. 4: 191-210.

BRIAN M.V. 1962: Studies of caste differentiation in Myrmica rubra L. 5. Social conditions affecting early larval differentiation. - Insectes Soc. 9: 295-310.

Brian M.V. 1970: Communication between queens and larvae in the ant Myrmica. - Anim. Behav. 18: 467-472.

BRIAN M.V. 1973a: Queen recognition by brood-rearing workers of the ant Myrmica rubra L. - Anim. Behav. 21: 691-698.

BRIAN M.V. 1973b: Caste control through worker attack in the ant Myrmica. - Insectes Soc. 20: 87-102.

BRIAN M.V. 1986: The importance of daylength and queens for larval care by young workers of the ant Myrmica rubra L. Physiol. Entomol. 11: 239-249.

Danilevsky A.S. 1961: Photoperiodism and Seasonal Development of Insects. Japanese translation by T. Hidaka \& S. Masaki, 1966. University of Tokyo Press, Tokyo, 293 pp.

Danks H.V. 1987: Insect Dormancy: An Ecological Perspective. Biological Survey of Canada, Ottawa, $439 \mathrm{pp}$.

Hahn D.A. \& Denlinger D.L. 2011: Energetics of insect diapause. - Annu. Rev. Entomol. 56: 103-121.

Hölldobler B. \& Wilson E.O. 1990: The Ants. Harvard University Press, Cambridge, 732 pp.

Japanese Ant Database Group (JADG) 2003: Super Visual Encyclopedia. Ants of Japan. Gakken, Tokyo, 196 pp. [in Japanese].

Kamitani S., Asakura K. \& Nakamura K. 2015: Effects of environmental factors on life cycle regulation in Lasius japonicus Santschi (Formicidae). - Sociobiology 62: 467-473.

KiPYATKov V.E. 1993: Annual cycles of development in ants: Diversity, evolution, regulation. - Proc. Coll. Soc. Ins. 2: 25-48.
KipyatKov V.E. 2001a: Seasonal life cycles and the forms of dormancy in ants (Hymenoptera: Formicoidea). - Acta Soc. Zool. Bohem. 65: 211-238.

KIPYATKOV V.E. 2001b: A distantly perceived primer pheromone controls diapause termination in the ant Myrmica rubra L. (Hymenoptera, Formicidae). - J. Evol. Biochem. Physiol. 37: 405-416.

Kipyatkov V.E. \& Lopatina E.B. 1999: Social regulation of larval diapause by workers of three species of the ant genus $M y r-$ mica Latreille (Hymenoptera, Formicidae). - Entomol. Rev. 77: 1138-1144.

KipyatKov V.E. \& Lopatina E.B. 2009: Temperature and photoperiodic control of diapause induction in the ant Lepisiota semenovi (Hymenoptera, Formicidae) from Turkmenistan. - $J$. Evol. Biochem. Physiol. 45: 238-245.

Kipyatkov V.E., Lopatina E.B. \& Pinegin A.Yu. 1996: Influence of the queen and worker ants on onset and termination of the larval diapause in Lasius niger (L.) (Hymenoptera, Formicidae). - Entomol. Rev. 76: 514-520.

Kipyatkov V.E., Lopatina E.B. \& Pinegin A.Yu. 1997: Social regulation of development and diapause in the ant Leptothorax acervorum (Hymenoptera, Formicidae). - Entomol. Rev. 77: 248-255.

KošŤÁL V. 2006: Eco-physiological phases of insect diapause. J. Insect Physiol. 52: 113-127.

LeEs A.D. 1955: The Physiology of Diapause in Arthropods. Cambridge University Press, Cambridge, $151 \mathrm{pp}$.

Masuko K. 2003a: Larval oophagy in the ant Amblyopone silvestrii (Hymenoptera, Formicidae). - Insectes Soc. 50: 317-322.

MAsUKo K. 2003b: Analysis of brood development in the ant Amblyopone silvestrii, with special reference to colony bionomics. —Entomol. Sci. 6: 237-245.

Mousseau T. \& Dingle H. 1991: Maternal effects in insect life histories. - Annu. Rev. Entomol. 36: 511-534.

Muramatsu N. \& Numata H. 2002: Seasonal changes in ovarian development and its control by photoperiod in the Japanese queenless ant, Pristomyrmex pungens. In: Proceedings XIV International Congress of IUSSI, Hokkaido University, 27 July-3 August 2002. Hokkaido University, Sapporo, p. 205.

NaKamura K., Fujiyama M. \& Ohta K. 2017: Effect of temperature on queen oviposition and seasonal colony development in Lasius japonicus (Hymenoptera: Formicidae). - Appl. Entomol. Zool. 52: 107-112.

SCHNEIRLA T.C. 1957: Theoretical consideration of cyclic processes in Doryline Ants. — Proc. Am. Phil. Soc. 101: 106-133.

Tauber M.J., Tauber C.A. \& Masaki S. 1986: Seasonal Adaptations of Insects. Oxford University Press, New York, 426 pp.

TSCHINKEL W.R. 1988: Social control of egg-laying rate in queens of the fire ant, Solenopsis invicta. - Physiol. Entomol. 13: 327-350.

WEIR J.S. 1959: The influence of worker age on trophogenic larval dormancy in the ant Myrmica. _ Insectes Soc. 6: 271-290.

Zar J.H. 2010: Biostatistical Analysis, 5th ed. Pearson Prentice Hall, Upper Saddle River, 944 pp.

Received November 19, 2017; revised and accepted November 13, 2018 Published online December 17, 2018 